\title{
Superparamagnetic nano-biocomposites for application as dielectric resonator antennas
}

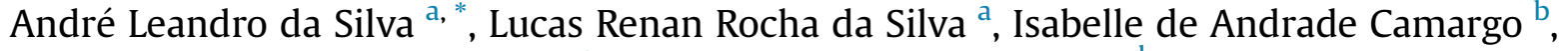 \\ Deuber Lincon da Silva Agostini ${ }^{\mathrm{c}}$, Juliano Casagrande Denardin ${ }^{\mathrm{d}}$, \\ Derval dos Santos Rosa b, Giuseppe Mele ${ }^{\mathrm{e}}$, Diego Lomonaco Vasconcelos de Oliveira ${ }^{\text {a }}$ \\ Pierre Basílio Almeida Fechine ${ }^{\mathrm{f}}$, Selma Elaine Mazzetto ${ }^{a}$ \\ a Department of Organic and Inorganic Chemistry, Federal University of Ceará, Rua do Contorno, S/N, CEP: 60451-970, Fortaleza, CE, Brazil \\ ${ }^{\mathrm{b}}$ Center for Engineering, Modeling and Applied Social Sciences, Federal University of ABC, Avenida dos Estados, 5001, CEP: 09210-580, Santo André, SP, \\ Brazil \\ ${ }^{c}$ Department of Physics, Chemistry and Biology, State University of São Paulo, Rua Roberto Simonsen, 305, CEP: 19060-900, Presidente Prudente, SP, Brazil \\ d Department of Physics, University of Santiago, Chile (USACH), Avenida Ecuador 3493, Santiago, Chile \\ e Department of Engineering for Innovation, University of Salento, Via Per Amesano Km 4, 73100, Lecce, Italy \\ ${ }^{\mathrm{f}}$ Department of Analytical Chemistry and Physical Chemistry, Federal University of Ceará, Rua do Contorno, S/N, CEP: 60451-970, Fortaleza, CE, Brazil
}

\section{H I G H L I G H T S}

- Nano-biocomposites for application as dielectric resonators are proposed.

- The synthesized magnetite has nanometric size and superparamagnetic character.

- All the nano-biocomposites also presented superparamagnetic behavior.

- All the nano-biocomposites have good rates of biodegradation in simulated soil.

- All the DRA's presented potential for technological use in broadband.

\section{A R T I C L E I N F O}

\section{Article history:}

Received 16 July 2016

Received in revised form

6 September 2016

Accepted 8 October 2016

Available online 13 October 2016

\section{Keywords:}

Cardanol

Bio-based thermoset plastic

Sponge gourd fiber

Magnetite

\begin{abstract}
A B S T R A C T
There is a growing global interest for the development of green technologies that allow the use of products with less damage to environment, as well as for maximum and sustainable use of natural resources. The main aim of this study was to develop superparamagnetic nano-biocomposites for application as dielectric resonator antennas, from a combination of a cardanol-based thermoset plastic, chemically modified sponge gourd fibers ( $\mathrm{NaOH} 10 \%$ and $\mathrm{NaClO} 1 \mathrm{wt} \%)$, and magnetite nanoparticles in different contents $(1,5$, and $10 \mathrm{wt} \%)$. The magnetite particles exhibited nanometric size, high purity and crystallinity, and superparamagnetic character. All nano-biocomposites showed superparamagnetic behavior, excellent thermal stability, good biodegradation rates, and better mechanical strength for the material with magnetite $10 \mathrm{wt} \%$. All dielectric resonator antennas showed satisfactory return loss and suitability for technological applications, especially for performance in broadband.
\end{abstract}

() 2016 Elsevier B.V. All rights reserved.

\section{Introduction}

The worldwide interest is increasing for the development of socalled "green" technologies which enable the use of products with a smaller environmental impact [1-4]. In parallel, public incentive

\footnotetext{
* Corresponding author.

E-mail address: andre.leandro@ufcg.edu.br (A.L. da Silva).
}

policies for the maximum and sustainable use of the natural resources are being strengthened.

The exploitation of raw materials of natural origin has been gaining great importance globally. The Food and Agriculture Organization of the United Nations (FAO-ONU) declared 2009 as being the international year of natural fibers. The greatest intention was to raise awareness and stimulate the use of these materials, also encouraging government incentive policies to the sector and to the sustainable business actions [5]. In this group of the natural fibers, 
the ones of plant origin stand out for being biodegradable, abundant, non-toxic and of low cost [6].

The present study opted for the sponge gourd (Luffa cylindrica), abundant fiber in Brazil and whose technological potential is still very little exploited, commonly used in handicraft and mainly in personal hygiene. This fiber is an excellent candidate to be used as dispersed phase in thermoset matrices, which provides the possibility of obtaining materials with desirable properties, adding value to the fiber. The value adding policy is also applied to the Cashew nutshell liquid-CNSL, a byproduct of the cashew agribusiness, commercialized at low prices and with little prominence, as the main star of this agribusiness is the Cashew Nut Almond (CNA). The resin derived from the CNSL presents itself as an alternative to the energetic matrix based on the fossil fuels, what strengthens the commitment with the environment and with the use of raw materials from renewable sources.

It is in the search for sustainability that several researches on polymeric materials and composites have been carried out to assure environmental preservation and the possibility of a better quality of life for society [7-10].

Steinhoff and collaborators [11] highlight that the production of plastic resins from biodegradable materials gains an increasing importance. The growing interest in these materials is due to possibilities of oil shortage and to the incentives to the exploitation of raw materials of natural origin.

This research concentrated on the development of superparamagnetic nano-biocomposites through the combination of a thermoset plastic derived from a byproduct of the cashew agribusiness (cardanol), chemically modified sponge gourd fiber, and magnetite nanoparticles. The ultimate aim of this research was to study the nano-biocomposites as dielectric resonator antennas (DRA's).

The magnetite nanoparticles were prepared by the coprecipitation method and studied by X-ray diffraction (XRD), Transmission electron microscopy (TEM), and Vibrating sample magnetometry (VSM). As for the nano-biocomposites they were characterized by Thermogravimetry (TG), Differential scanning calorimetry (DSC), Dynamic-mechanical analysis (DMA), Scanning electron microscopy (SEM), Vibrating sample magnetometry (VSM), Biodegradation testing in simulated soil, and investigation of the resonators' behavior.

\section{Material and methods}

The alkaline treatment of the sponge gourd fiber, the obtainment of the cardanol from technical CNSL, and the preparation of the prepolymer resol were previously described [12].

\subsection{Synthesis of magnetite nanoparticles}

The magnetite nanoparticles $\left(\mathrm{Fe}_{3} \mathrm{O}_{4}\right)$ were synthesized by the coprecipitation method $[13,14]$, in which $4.587 \mathrm{~g}(0.0165 \mathrm{~mol})$ of $\mathrm{FeSO}_{4} \cdot 7 \mathrm{H}_{2} \mathrm{O}$ (Dinâmica, $99 \%$ ) and $8.919(0.033 \mathrm{~mol})$ of $\mathrm{FeCl}_{3} \cdot 6 \mathrm{H}_{2} \mathrm{O}$ (Vetec, 97-102\%) were weighed, dissolved separately in $150 \mathrm{~mL}$ of distilled water (molar ratio $\mathrm{Fe}^{2+}: \mathrm{Fe}^{3+}=1: 2$ ), and mixed in a beaker $(500 \mathrm{~mL})$. The mixture was heated at $80{ }^{\circ} \mathrm{C}$ in a hot plate under constant mechanical agitation (1000 rpm) and after that $10 \mathrm{~mL}$ of $\mathrm{NH}_{4} \mathrm{OH}$ (Dinâmica, 28-30\%) was added, being observed the formation of a black precipitate, referent to the nanoparticle of interest.

After the coprecipitation, the suspension was maintained under agitation for $30 \mathrm{~min}$ for the growth of crystals. Posteriorly, the black precipitate was washed with distilled water $(3 \times 500 \mathrm{~mL})$ until reaching a neutral $\mathrm{pH}$ (verified with $\mathrm{pH}$ indicator paper-Merck), decanted with the aid of a magnet and the supernatant removed.
To avoid oxidation, the nanoparticles were transferred to a Petri dish and vacuum-packed in a desiccator until completely dried.

\subsection{Preparation of the nano-biocomposites}

The nano-biocomposites were prepared by the insertion of fixed mass of sponge gourd fiber (15\%) and from the impregnation of different contents of magnetite $(1,5$, and $10 \%)$. The resol and the epoxy resin (Diglycidyl ether of bisphenol-A, Avipol) were mixed in a beaker $(500 \mathrm{~mL})$, homogenized with the aid of a hot plate $\left(\sim 50^{\circ} \mathrm{C}\right)$ and glass rod. Posteriorly, the sponge gourd fiber was added to the mixture and followed by the addition of magnetite. After complete homogenization, the beaker was taken to the chapel of exhaustion and the crosslinking agent diethylenetriamine - DETA (SigmaAldrich, 99\%) was added with the aid of a disposable plastic syringe. The system was slowly mixed with a glass rod, transferred to a mold, and submitted to the curing process. In Tables 1-3 are contained the compositions of the nano-biocomposites.

The molds used (Circular plastic molds with $20 \mathrm{~mm}$ high and $60 \mathrm{~mm}$ of diameter) were previously waxed with natural demolder (Carnauba wax). The curing of all the materials was carried out at room temperature in a chapel of exhaustion for a period of $48 \mathrm{~h}$, to ensure the total release of DETA. Next, the materials were postcured in an oven at $100{ }^{\circ} \mathrm{C}$ for $4 \mathrm{~h}$. The choice of these conditions was defined based on previous study [12].

\subsection{Scanning electron microscopy (SEM)}

The nano-biocomposites were previously covered with a thin layer of gold in a Metallizer Q150R ES (Quorum). The micrographs were obtained after cryogenic rupture in a Scanning electron microscope EVO LS15 (Carls Zeiss), with accelerating voltage of $30 \mathrm{kV}$.

\subsection{Transmission electron microscopy (TEM)}

The transmission electron micrographs of the magnetite nanoparticles were obtained using a Jeol JEM-1011 equipment, operating in $100 \mathrm{kV}$ and equipped with a CCD Orius 831 (Gatan) camera. The samples were diluted, placed in carbon grades, and coated with copper. Next, they were dried at $60{ }^{\circ} \mathrm{C}$ for $24 \mathrm{~h}$ before obtaining the micrographs. The approximate size of the particle was estimated based on the average value of 50 measures made by means of the treatment of the transmission electron micrograph using the MBRuler, tool for the measurement of distances and angles.

\subsection{X-ray diffraction (XRD)}

The X-ray diffraction profiles of the magnetite were obtained at a temperature of $300 \mathrm{~K}$, using a Diffractometer MPD (Xpert Pro), with a Cu tube in $40 \mathrm{kV}$ (Voltage), $30 \mathrm{~mA}$ (Current), in the interval of $15^{\circ}$ to $100^{\circ}$ in $2 \theta$. The refinement of the nanoparticles was carried out using the Rietveld method [15], which allows an adjustment of the instrumental parameters of the previously identified crystalline structure. The softwares used in the identification and refinement of the magnetite were the XPert High Score Plus [16] and the DBWS-Tools 2.3 [17], respectively.

The widths at half height (FWHM-Full Width at Half Maximum) of the main peaks of diffraction of the magnetite nanoparticles obtained after the refinement, which were extracted from the output file of the DBWS program, were used to calculate the average size of the particles using the Scherrer equation [18].

\subsection{Thermogravimetry (TG)}

The TG curves of the nano-biocomposites were obtained in a TG 
Table 1

Composition of the nano-biocomposite with magnetite $1 \%$.

\begin{tabular}{|c|c|c|c|}
\hline Components & Mass (g) & Percentage of each component in the system (\%) & Proportion of the matrix components (\% wt/wt) \\
\hline Prepolymer resol & 17.63 & 38.37 & 93 \\
\hline Epoxi & 18.89 & 41.11 & 100 \\
\hline DETA & $2.07(2.17 \mathrm{~mL})$ & 4.50 & 11 \\
\hline Sponge gourd fiber & 6.89 & 15 & - \\
\hline Magnetite & 0.459 & 1 & - \\
\hline
\end{tabular}

Table 2

Composition of the nano-biocomposite with magnetite $5 \%$.

\begin{tabular}{|c|c|c|c|}
\hline Components & Mass (g) & Percentage of each component in the system (\%) & Proportion of the matrix components (\% wt/wt) \\
\hline Prepolymer resol & 16.79 & 36.55 & 93 \\
\hline Epoxi & 17.99 & 39.16 & 100 \\
\hline DETA & $1.97(2.07 \mathrm{~mL})$ & 4.29 & 11 \\
\hline Sponge gourd fiber & 6.89 & 15 & - \\
\hline Magnetite & 2.29 & 5 & - \\
\hline
\end{tabular}

Table 3

Composition of the nano-biocomposite with magnetite $10 \%$.

\begin{tabular}{|c|c|c|c|}
\hline Components & Mass (g) & Percentage of each component in the system (\%) & Proportion of the matrix components (\% wt/wt) \\
\hline Prepolymer resol & 15.74 & 34.26 & 93 \\
\hline Epoxi & 16.87 & 36.72 & 100 \\
\hline DETA & $1.85(1.95 \mathrm{~mL})$ & 4.02 & 11 \\
\hline Sponge gourd fiber & 6.89 & 15 & - \\
\hline Magnetite & 4.59 & 10 & - \\
\hline
\end{tabular}

STA 6000 (Perkin Elmer) equipment, under an atmosphere of $\mathrm{N}_{2}$ (Flow rate of $50 \mathrm{~mL} / \mathrm{min}$ ), heating rate of $10^{\circ} \mathrm{C} / \mathrm{min}$ in a temperature range between 30 and $600^{\circ} \mathrm{C}$. A platinum pan containing $3 \mathrm{mg}$ of sample was used. The parameter used for the determination of the initial degradation temperature was the Tonset [19], obtained by the intersection of a tangent drawn between the superior, inferior horizontal base lines and the steep part of the sigmoid curve, characterized as the point which best represents the degradation temperature of a compound.

\subsection{Differential scanning calorimetry (DSC)}

The DSC curves of the nano-biocomposites were obtained in a DSC Q-20 (TA Instruments) equipment, in an atmosphere of $\mathrm{N}_{2}$ (Flow rate of $50 \mathrm{~mL} / \mathrm{min}$ ), heating rate of $10{ }^{\circ} \mathrm{C} / \mathrm{min}$ in a temperature range between 30 and $400{ }^{\circ} \mathrm{C}$. A hermetic aluminum pan was used containing $2.5 \mathrm{mg}$ of sample. The temperature of glass transition ( $\mathrm{Tg}$ ) was calculated from the DSC curves by the insertion of a horizontal line drawn at half the height of the step and of the tangent drawn by the inflexion point, according to the standardization of the norm ASTM D3418 [20].

\subsection{Dynamic-mechanical analysis (DMA)}

The dynamic-mechanical tests were carried out for the nanobiocomposites in an equipment DMA 204 (Netzsch), in a synthetic air environment, frequency of $1 \mathrm{~Hz}$, heating rate of $5^{\circ} \mathrm{C} / \mathrm{min}$ at a temperature range between -20 and $140^{\circ} \mathrm{C}$, using traction as mechanical solicitation. The specimens had dimensions of $15 \mathrm{~mm}$ high, $4 \mathrm{~mm}$ wide, and $3 \mathrm{~mm}$ thick. The tests were conducted based on the norm ASTM D5026 [21]. The temperature of glass transition $(\mathrm{Tg})$ was calculated by the method which uses the temperature measured by the intersection of the tangent lines of the storage modulus curve $\left(E^{\prime}\right)$, according to the standardization in the norm ASTM D7028 [22].

\subsection{Vibrating sample magnetometry (VSM)}

The magnetization measurements were carried out at a temperature of $300 \mathrm{~K}$ with a Vibrating sample magnetometer. The equipment was previously calibrated using a pure nickel thread. The samples were duly weighed and the magnetization was expressed in emu/g.

\subsection{Biodegradation testing in simulated soil}

The simulated soil used in the biodegradability tests of the nano-biocomposites was prepared with $23 \%$ of clayey loam, $23 \%$ of organic matter (bovine manure), $23 \%$ of urea, and $34 \%$ of distilled water (All wt). The specimens were prepared with $3 \mathrm{~mm}$ thick and with an irregular form. For the tests, the samples were weighed, buried in simulated soil in a plastic tray at a temperature of $297 \mathrm{~K}$, and maintained humidified by adding distilled water weekly. The biodegradation was investigated for a period of 80 days through the monitoring of the mass variation. Periodically, the samples were removed from the soil, washed with distilled water, dried at room temperature, and weighed. Next, they were buried again in their respective soils. The experiments were performed in quadruplicate.

\subsection{Test of the nano-biocomposites as dielectric resonator antenna (DRA)}

Cylindrical dielectric resonators were manufactured with $2 \mathrm{~cm}$ of diameter and $1 \mathrm{~cm}$ thick (ratio radius/height $=1: 1$ ) from the nano-biocomposites. These dimensions were chosen for a better electromagnetic connection of the mode $\mathrm{TE}_{011}$ with the dielectric resonator and a greater radiation confinement, which allows an increase in the quality factor, as foreseen by the Hakki-Coleman method [23].

For the test as DRA, the resonators were positioned in a ground plane made of copper and excited by a lateral coaxial probe 
(metallic thread), according to the experiment described by Long and collaborators [24]. To perform the connection with the coaxial probe, the DRA was placed in different positions until the obtainment of a good response. Fig. 1 shows the test carried out with the DRA's manufactured in this study.

The dielectric permissiveness was estimated by the study of the DRA's by the analysis of the mode $\mathrm{HE}_{11 \delta}$, which is the dominant mode of a DRA fed laterally by a coaxial probe. The frequency of this mode is given by the equation [25]:

$f H E_{11 \delta}=\frac{6,324 c}{2 \pi a \sqrt{\varepsilon_{r}^{\prime}+2}}\left[0,27+0,36\left(\frac{a}{2 h}\right)-0,02\left(\frac{a}{2 h}\right)^{2}\right]$

where $c$ is speed of light, $a$ and $h$ are the radius and height of the dielectric resonator, respectively, and $\varepsilon_{\mathrm{r}}^{\prime}$ is the dielectric permissiveness.

The dielectric permissiveness was calculated by Equation (1), where the values of the dimensions are known and the value of the resonant frequency of the $\mathrm{HE}_{11 \delta}$ mode is obtained by a network analyzer.

\section{Results and discussion}

\subsection{Characterization of the magnetite nanoparticles}

The identification of the synthesized magnetic nanoparticle was made by the comparison with the diffractometric pattern provided by the Inorganic Crystal Structure Database (ICSD).

The data obtained from the XRD was treated with the aid of the DBWS-Tools 2.3 program and refined by the Rietveld method. The result of the refinement applied to the magnetite nanoparticle is in Fig. 2, where it is showed the relative intensity of the peaks obtained by the observed result (black line), calculated result (red line), and the difference between them (blue line) in $2 \theta$.

The magnetite nanoparticles unit cell parameters were $8.35 \AA$ $(\mathrm{a}=\mathrm{b}=\mathrm{c})$, angles of $90^{\circ}$, cell volume of $582.818 \AA$, and cell density of $5.205 \mathrm{~g} / \mathrm{cm}^{3}$, typical of a cubic structure. The refined agreements were $R_{p}=13.71 \%, R_{w p}=17.96 \%$, and $S=1.04$.

In the XRD profile well defined peaks were identified, evidencing high crystallinity, located in diffraction angles in $2 \theta$ of $18.505^{\circ}, 30.358^{\circ}, 35.736^{\circ}, 37.376^{\circ}, 43.406^{\circ}, 53.823^{\circ}, 57.369^{\circ}$, $62.990^{\circ}, 71.454^{\circ}, 74.511^{\circ}, 79.511^{\circ}, 87.359^{\circ}, 90.281^{\circ}$, and $95.156^{\circ}$, represented, respectively, by the crystallographic planes (111), (220), (311), (222), (400), (422), (511), (440), (620), (533), (444), (642), (553), and (800), corresponding to a cubic crystalline structure of the inverse spinel type, typical of the magnetite (ICSD 82449) [26]. Only a single phase was identified, certifying the purity of the synthesized nanoparticle and the average size of the particle, calculated by the Scherrer equation, was of approximately $13 \pm 0.75 \mathrm{~nm}$.

The Transmission electron microscopy is widely used in researches with nanoparticles, due to this technique capacity of exhibiting images at a significantly higher resolution in comparison to other types of microscopies. In this study, the TEM was an important tool to study the morphology of the synthesized magnetic nanoparticles, whose transmission electron micrograph obtained can be found in Fig. 3.

The magnetite nanoparticles presented a spherical shape, which is very desirable, seen as good magnetic properties are exhibited when there is a rounded morphology [27]. The average particle size was $11.6 \pm 1.3 \mathrm{~nm}$, value close to the size calculated from the XRD data.

It is known that the magnetite nanoparticles with a grain size inferior to $30 \mathrm{~nm}$ presents the superparamagnetism property [28-30]. This property is of extreme importance when nanoparticles are used for the development of materials, as the superparamagnetic character reduces the agglomeration when the external field is removed [31]. The magnetization curve obtained for the magnetite is in Fig. 4.

Values of coercivity or reminiscent magnetization were not observed, which proves the already expected superparamagnetic character, due to the size of grain determined by XRD and TEM. The synthesized magnetite nanoparticle presented saturation magnetization of $35.3 \mathrm{emu} / \mathrm{g}$. This value is in accordance to what is reported in literature $[32,33]$ for the nanoparticulate magnetite, in which the saturation magnetization is situated between 30 and 60 $\mathrm{emu} / \mathrm{g}$.

\subsection{Characterization of the nano-biocomposites}

The nano-biocomposites were prepared from the combination of the thermorigid plastic derived from the cardanol, sponge gourd fiber treated with $\mathrm{NaOH} 10 \%$, treatment defined in a previous study [12], and superparamagnetic magnetite nanoparticles. For convenience, the nano-biocomposites impregnated with 1,5 , and $10 \%$ of magnetite nanoparticles will be called BMAG1, BMAG5, and BMAG10, respectively. The maximum content of impregnated magnetite was of $10 \%$, respecting the proposal of the Nanotechnology of enabling considerable gains in certain properties using small contents of the nanoparticulate phase [34]. In addition, according to literature [35], superior quantities tend to present incorporation problems and increase the tendency to agglomeration, independent of the size of the particles.

The DSC curves were obtained for the nano-biocomposites with the aim of identifying important transitions through the enthalpy variations (Fig. 5).

BMAG1, BMAG5, and BMAG10 presented a variation in the base line in approximately 59,60 , and $59^{\circ} \mathrm{C}$, respectively, correspondent to the $\mathrm{Tg}$ of the materials. Zhao and $\mathrm{Li} \mathrm{[36]} \mathrm{also} \mathrm{observed} \mathrm{that} \mathrm{the}$ addition of 5, 10, and $15 \%$ (wt) of alumina nanoparticles to an epoxy matrix did not cause considerable alterations in the $\mathrm{Tg}$, independent of the content.

No exothermic event of residual heat was identified for the materials, which shows that the processing conditions enabled the conversion and complete curing for the nano-biocomposites.

At approximately 174,162 , and $172{ }^{\circ} \mathrm{C}$ were observed small endothermic events for BMAG1, BMAG5 and BMAG10, respectively, corresponding to the elimination of water. An intense endothermic event, attributed to the degradation of the materials, was identified at 288, 289 and $302{ }^{\circ} \mathrm{C}$ for BMAG1, BMAG5 and BMAG10, respectively.

The variation of the mass of the nano-biocomposites in function of the temperature was studied by Thermogravimetry, whose TG and DTG curves of the materials are in Fig. 6. Between 30 and $160{ }^{\circ} \mathrm{C}$ occurred a small loss of mass of approximately $2.76,3.29$, and $4.08 \%$ for BMAG1, BMAG5, and BMAG10, respectively, corresponding to the dehydration process, as already observed by DSC.

The TG curves showed that BMAG1, BMAG5, and BMAG10 maintain very similar thermal stabilities up to approximately 315 , 318 , and $310^{\circ} \mathrm{C}$, respectively. The DTG curves showed the occurrence of two stages of mass loss. The first, corresponding to the start of the degradation of the materials, is related to the simultaneous degradation of lignin, hemicellulose, cellulose [37-40] and also of the flexible segments of the polymeric matrix. The second stage concerns the degradation of the rigid segments of the matrix. The magnetite nanoparticles are thermally stable in the studied temperature interval. At the end of the two stages, BMAG1, BMAG5, and BMAG10 presented $15.25,17.12$, and $25.51 \%$ of residues, respectively.

The Dynamic-mechanical analysis is an extensively used 


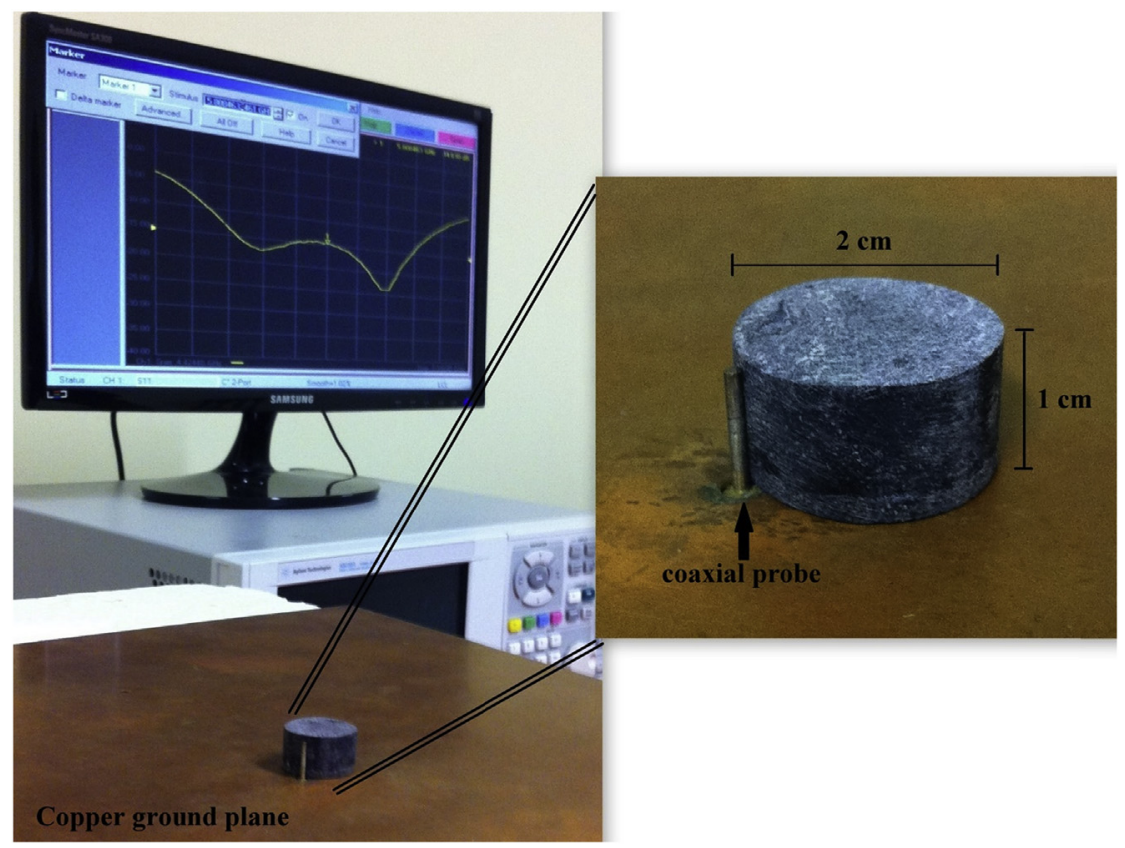

Fig. 1. Test carried out with the DRA's.

technique to study polymeric systems, serving as a parameter to assess the mechanical characteristics [41] and it was conducted to study the influence of the different contents of nanoparticles added to the materials in their viscoelastic behavior.

The storage modulus $\left(E^{\prime}\right)$ represents the elastic contribution or the energy stored in the materials, and the loss modulus $\left(E^{\prime \prime}\right)$ is in regard to the viscous behavior or the energy dissipated during the test $[42,43]$. The profiles of storage and loss modulus of the nanobiocomposites in function of the temperature are in Fig. 7.

The Tg for BMAG1, BMAG5, and BMAG10 was 64,59 , and $63{ }^{\circ} \mathrm{C}$, respectively, being these values close to those determined by DSC. It was observed that for all the nano-biocomposites the value of $\mathrm{E}^{\prime}$ decreased continuously according to the increase of the temperature and no corresponding increment to a possible residual heat was detected, reinforcing what was observed by DSC regarding the complete curing of the materials.

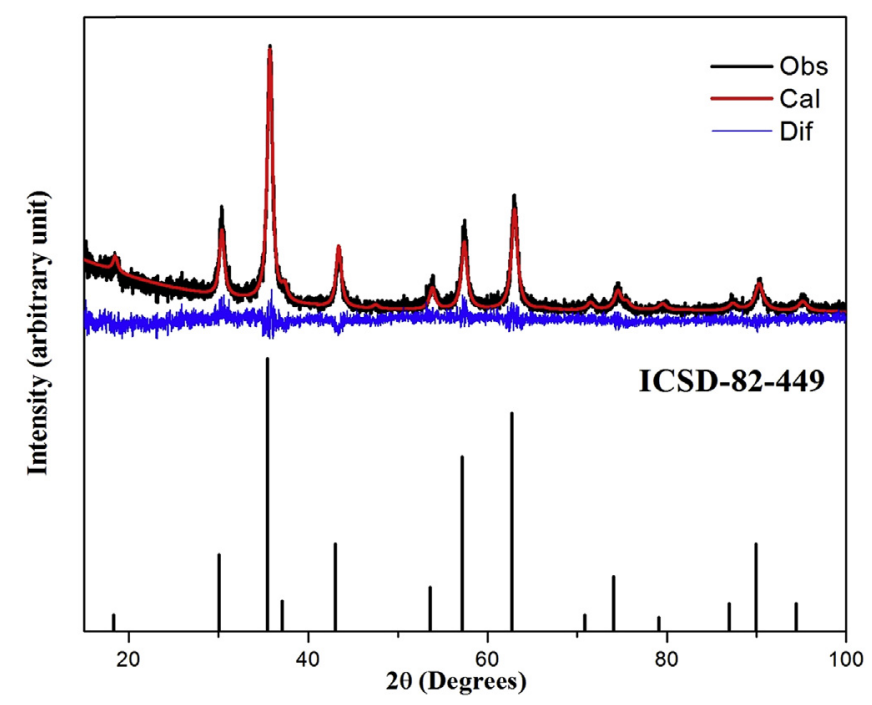

Fig. 2. XRD profile of the synthesized magnetite nanoparticles and ICSD diffractometric pattern of magnetite.
$E^{\prime}$ is intimately related to the material's capacity to support mechanical load with recoverable deformation. In other words, this parameter concerns the rigidity of the material [44]. It was found that the materials presented distinct values of $\mathrm{E}^{\prime}$ in all the region of the vitreous state. At $30^{\circ} \mathrm{C}$, for example, were observed values of $\mathrm{E}^{\prime}$ around 1458; 1612; and $2008 \mathrm{MPa}$ for BMAG1, BMAG5, and BMAG10, respectively. At this temperature, occurred an increase in $\mathrm{E}^{\prime}$ as greater the level of added nanoparticles, in which the nanobiocomposites containing 5 and 10\% of magnetite had an increase of 11 and $38 \%$ in rigidity, respectively, compared to the one which contains only $1 \%$. Lim and collaborators [45] also found in nanocomposites of epoxy matrix that the addition of 2.5 and $5 \%$ (wt) of aluminum oxide nanoparticles propitiated increments of 17 and $24 \%$ in the rigidity of the materials, respectively.

If the mechanical energy received is not stored, it is then dissipated in the form of heat by molecular friction [46]. This way, it was observed that the values of $E^{\prime \prime}$ presented increments according to the increase of the temperature, which is coherent, seen as the temperature benefits the internal molecular movement and, therefore, the energy released. It was found that the value of $E^{\prime \prime}$ in all the temperature range which precedes the glass transition decreased as the impregnated nanoparticle content increased, indicating that the addition of magnetite attenuates the internal friction and, consequently, reduced the energy dissipation.

The magnetic properties of the materials were studied by Vibrating sample magnetometry (VSM), whose results are in Fig. 8.

The magnetization curves obtained presented profiles with no values of coercivity or reminiscent magnetization, which proves that all the nano-biocomposites are superparamagnetic. BMAG1, BMAG5, and BMAG10 presented saturation magnetization of 0.37 , 1.74 , and $3.51 \mathrm{emu} / \mathrm{g}$, respectively. These values present coherence with the content of impregnated nanoparticles, seen as saturation magnetization and magnetite content were directly proportional.

It is of fundamental importance to emphasize that the values of magnetization obtained by VSM correspond to the total mass of the analyzed sample, as well as to remember that to the nanobiocomposites were added 1, 5, and 10\% of nanoparticles (All wt). When analyzing the values of saturation magnetization found for BMAG1, BMAG5, and BMAG10, it was observed that they 

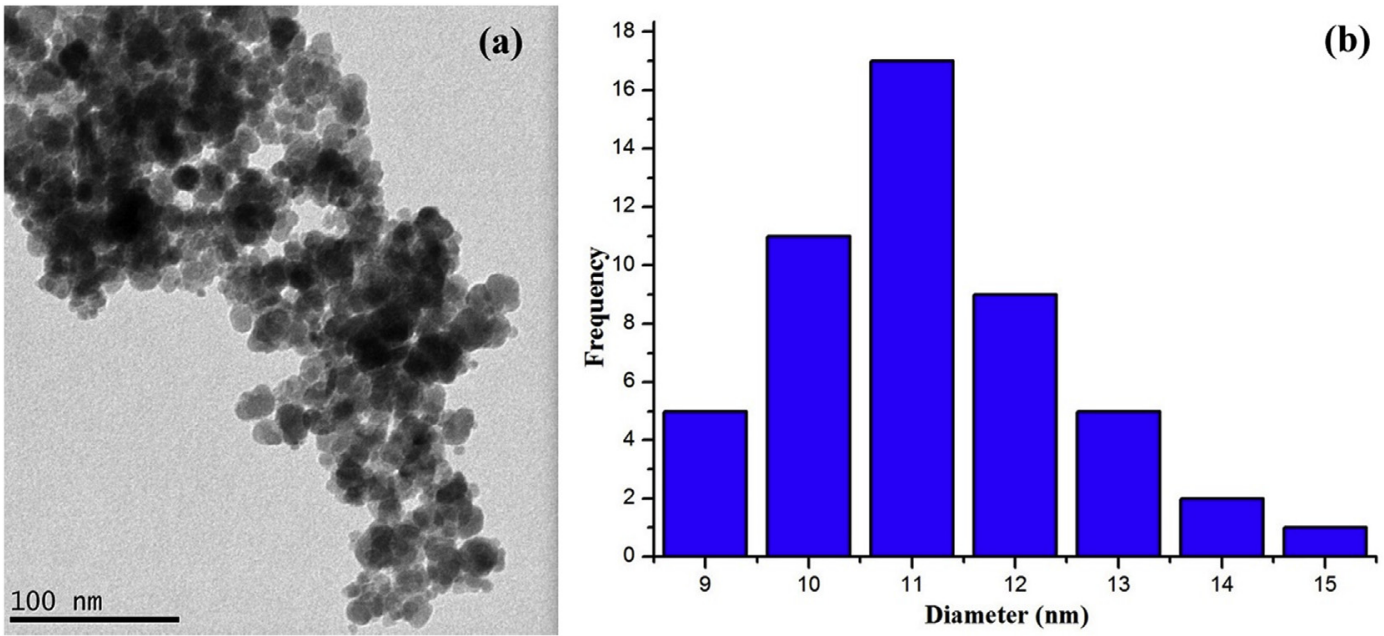

Fig. 3. (a) transmission electron micrograph and (b) size distribution of magnetite nanoparticles.

correspond approximately and respectively to 1,5 , and $10 \%$ of saturation magnetization of the magnetite, which was of $35.3 \mathrm{emu} /$ g. These results show that the magnetite maintained its integrity after the impregnation and that there was no formation of any additional phase or any interactions which could alter its performance or magnetic behavior. It can be said that these values reveal good conditions of preparation of the materials, besides a good dispersion of the magnetic nanoparticles in the polymeric matrix.

The scanning electron micrographs obtained for the nanobiocomposites after cryogenic fracture are in Fig. 9, where all the materials presented shallow vacancies on the surface, attributed to the curing reaction, which is exothermic, air incorporated during the preparation or still presence of water formed in the synthesis of the prepolymer resol.

BMAG10 presented a greater quantity of vacancies compared to BMAG5 e BMAG1, suggesting that the greater content of impregnated magnetite may have intensified the exothermy of the curing reaction and/or the release of water.

Another important finding made from the micrographs is the absence of aggregates which could be associated to the agglomeration of the nanoparticles, confirming their good dispersion in the polymeric phase, according to what was previously found by VSM.

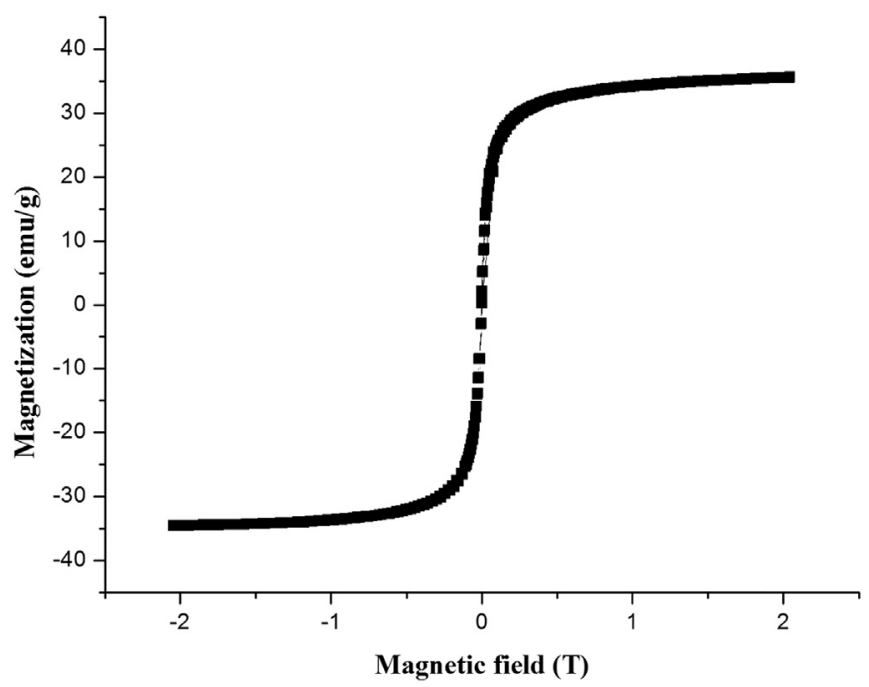

Fig. 4. Magnetization curve of the magnetite nanoparticles.
All the nano-biocomposites showed different rates of biodegradation in the investigated period and did not present profiles (Fig. 10) which may be directly related with the content of magnetite, which indicates the content of impregnated nanoparticles did not affect the biodegradation rate proportionally.

During 80 days of investigation, BMAG1, BMAG5, and BMAG10 exhibited biodegradation rates of $86 \pm 0.7,46 \pm 2.7$, and $54 \% \pm 2.3 \%$, respectively. Considering that the results of DSC, DMA, VSM, and SEM attested good conditions of preparation of the materials (Complete curing and homogeneity), it is ruled out the possibility of this variation in the biodegradation behavior being associated to faults in the processing. In a general way, all the nanobiocomposites presented good natural biodegradation rates in the period of time studied.

\subsection{Application of the nano-biocomposites as dielectric resonator antenna}

In Fig. 11 below is one of the dielectric resonators prepared in this study.

According to Kraus [47], as it is a system which irradiates electromagnetic energy, a DRA can be characterized by its efficiency

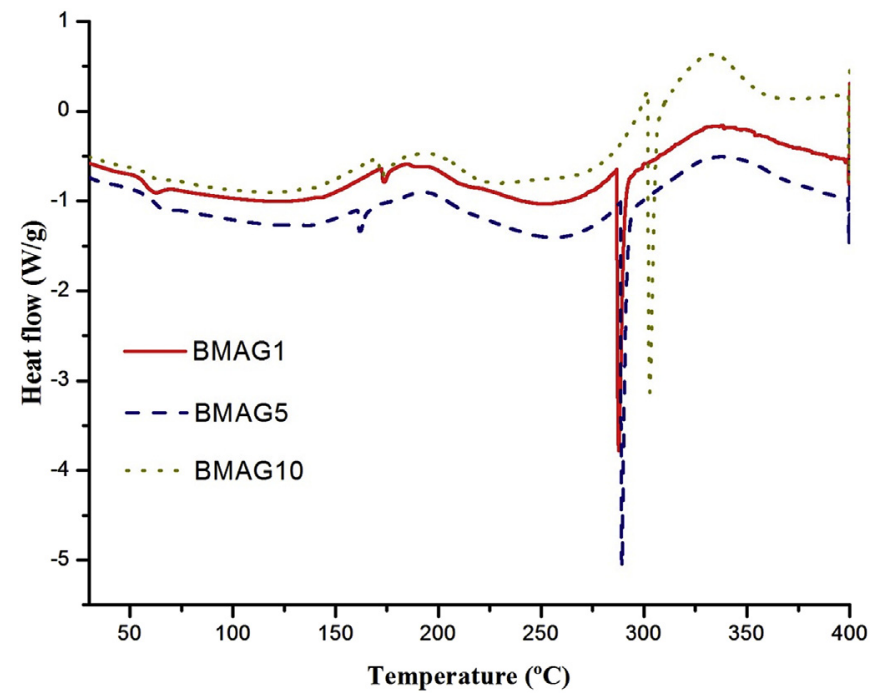

Fig. 5. DSC curves of the nano-biocomposites. 

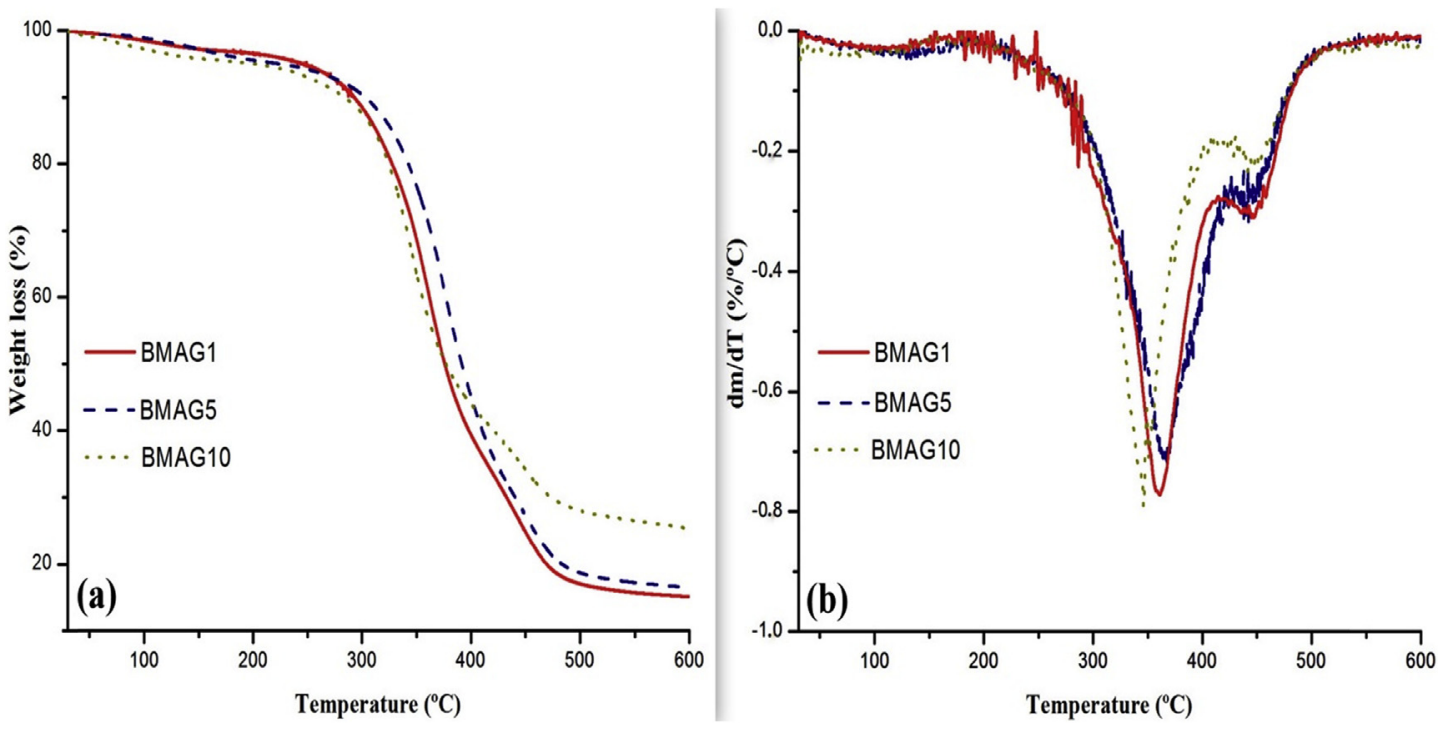

Fig. 6. (a) TG and (b) DTG curves of the nano-biocomposites.

and distribution of irradiated energy via the field, within the known spectrum. In Fig. 12 and in the Table 4 are the experimental results obtained for the nano-biocomposites acting as DRA.

The return loss values are very important, because they indicate how much energy from the resonator is reflected. When the value is close to $0 \mathrm{~dB}$, it means all energy is returning to the source. However, the more the value decrease, the less the energy returns and the greater is the irradiation.

Considering that an antenna with a return loss below $-10 \mathrm{~dB}$ may be used for commercial and technological purposes [25], it was observed that all the developed resonators complied with this requirement, demonstrating their potential for the application as DRA's. Although the magnetite did not affect proportionally the RL, it was observed that the larger additions of magnetic nanoparticles increased the irradiation and, consequently, reduced the RL of BMAG5 and BMAG10 in relation to the BMAG1.

It was found that the increase in the magnetite content did not cause any modification in $\varepsilon_{\mathrm{r}}^{\prime}$ or $\mathrm{f}_{\mathrm{o}}$ of the resonator BMAG5, when compared to the BMAG1. As for the BMAG10 it was observed a small increment in $\varepsilon_{\mathrm{r}}^{\prime}$ and a small displacement for a smaller operational $\mathrm{f}_{\mathrm{o}}$.

Regarding the BW, Balanis [48] defines it as a range of frequency in which the antenna presents an effective performance and generally is centered in the resonant frequency. The BW of the DRA's was verified in $-10 \mathrm{~dB}$ in the return loss graph, where it was observed that the variation of the content of magnetic nanoparticles did not cause any considerable alterations. The use of magnetite in nanocomposites for antenna-feeder systems is very desirable, once according to literature [49] magnetic nanoparticles allow to process materials with the suitable magnetic properties.

In a general way, all the DRA's presented good results of BW and exhibited a particular potential for broadband operation. Petosa [25] emphasizes that antennas which operate in broadband are very desirable, due to the constant growth in the field of communications. He also adds that relatively simple resonators which present broadband performance may be used as antennas in
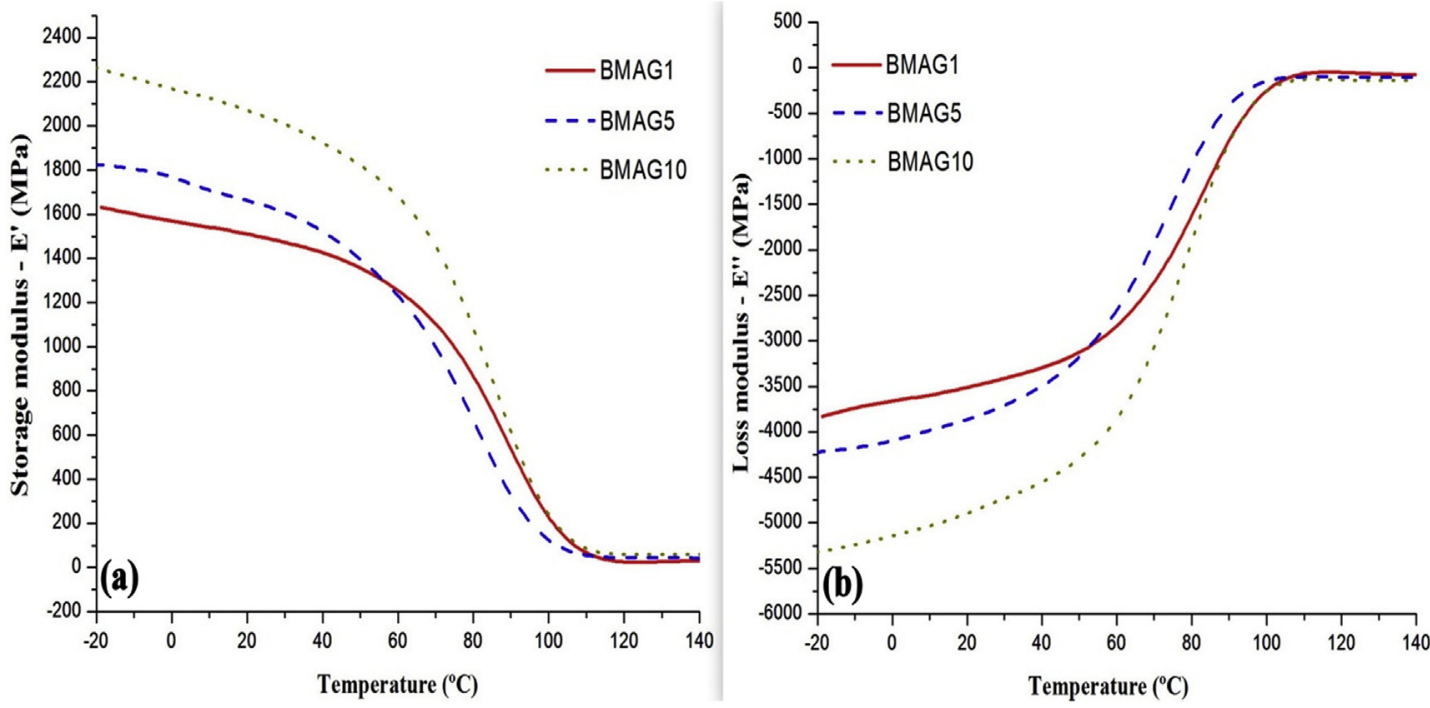

Fig. 7. Profiles of (a) storage modulus and (b) loss modulus of the nano-biocomposites. 


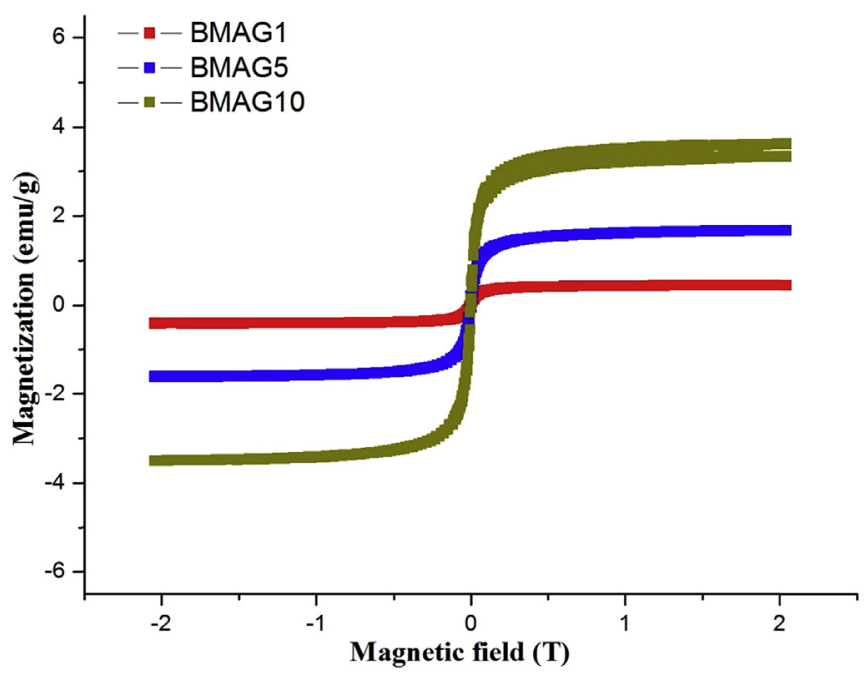

Fig. 8. Magnetization curves of the nano-biocomposites.

several applications.

Furthermore, the dielectric resonators offer the possibility and facility of adjustment of the system's parameters by means of alteration in geometry, dimensions or mode of excitement $[25,50]$, increasing even more the versatility and importance of these devices.

\section{Conclusion}

In a general way, the efforts of this research have been centered on the preparation of nano-biocomposites for the immediate application as dielectric resonators. For this purpose, the cardanol

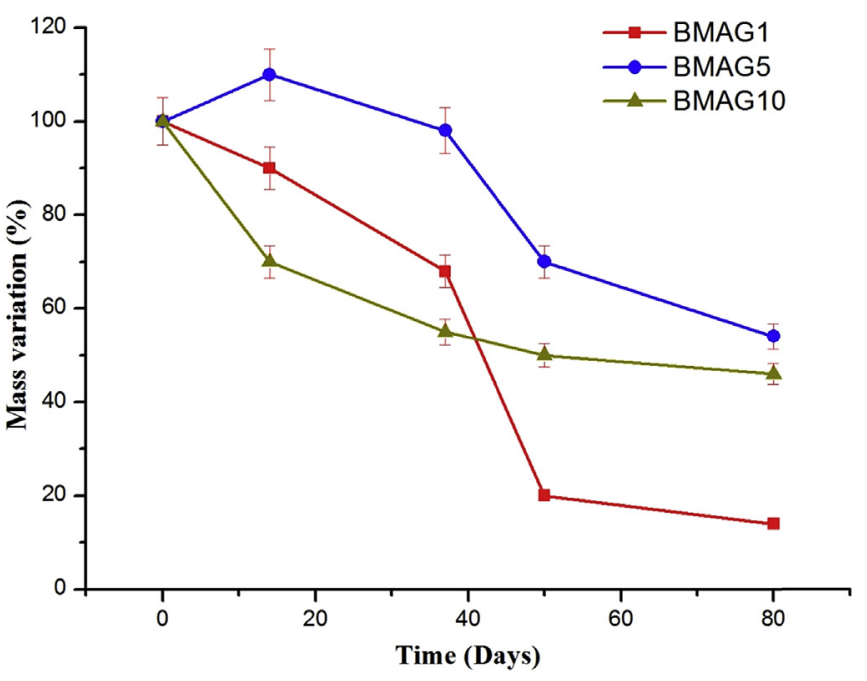

Fig. 10. Biodegradation profile of the nano-biocomposites.

was separated from the technical CNSL and used as an alternative to the petrochemical phenol for the development of a polymeric matrix. The sponge gourd fiber was used as a mechanical reinforcement and magnetite nanoparticles allowed specific properties to the final materials, highlighting the superparamagnetism.

The synthesized magnetite presented nanometric size, spherical shape, high purity and crystallinity, and superparamagnetic character. While in the investigations of the nano-biocomposites, the complete curing of all materials was confirmed and it was observed that the different contents of magnetite do not alter considerably the $\mathrm{Tg}$. All the nano-biocomposites presented superparamagnetic character, good rates of biodegradation in simulated soil, exhibited excellent thermal stability, and it was established that BMAG10 has

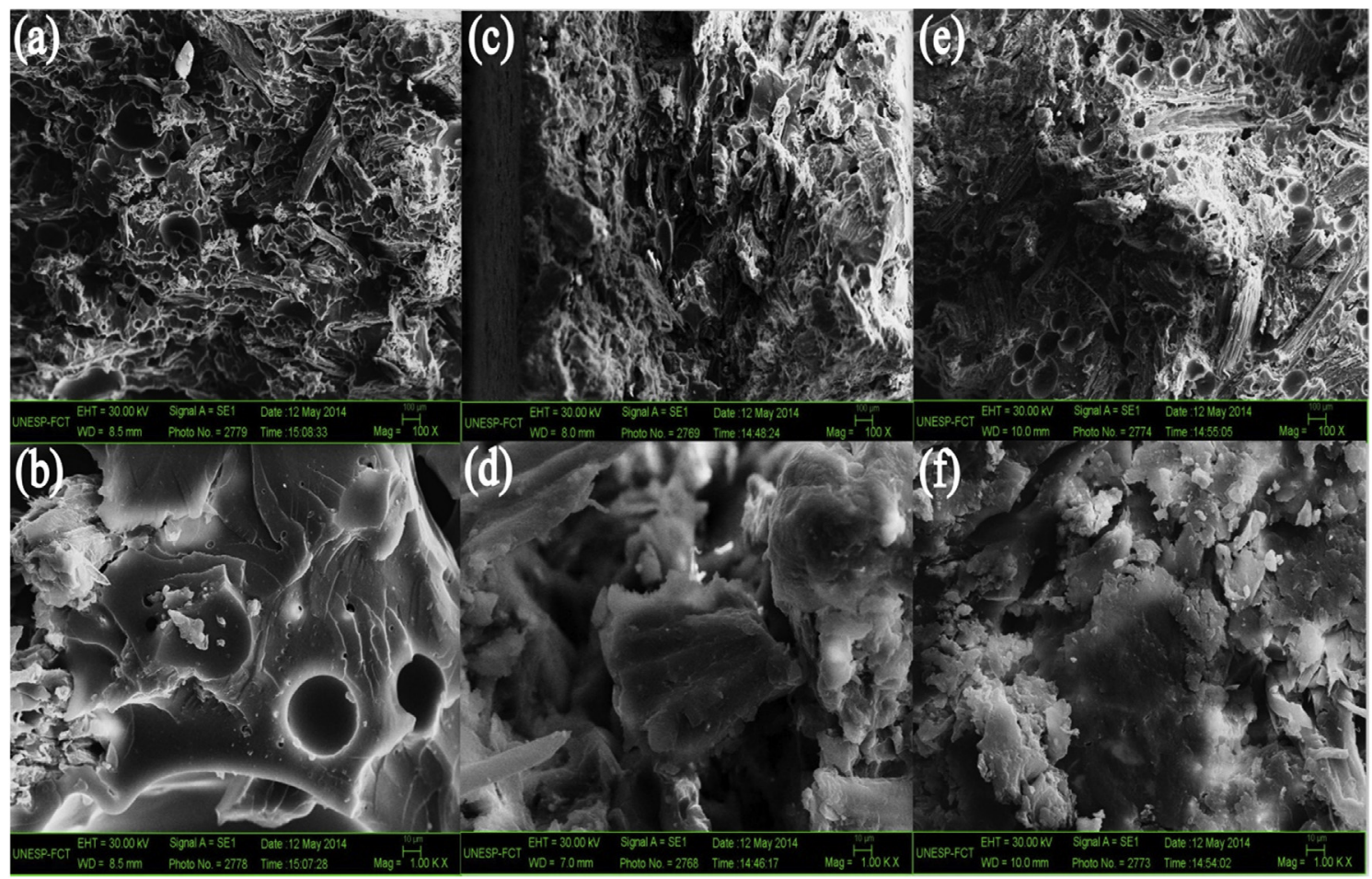

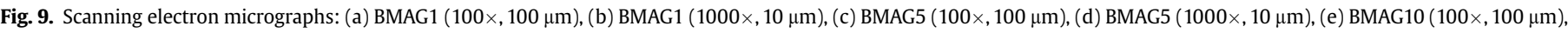
(f) $\operatorname{BMAG10}(1000 \times, 10 \mu \mathrm{m})$. 


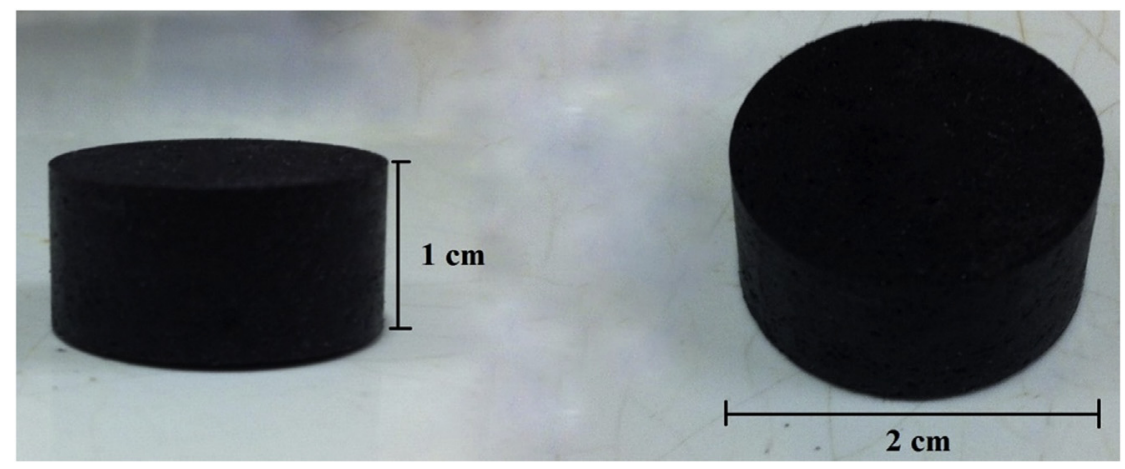

Fig. 11. One of the dielectric resonators prepared in this study.

greater mechanical resistance.

Concerning the dielectric resonators test, BMAG5 and BMAG10 presented greater irradiations and lower return losses in relation to BMAG1. Only BMAG10 presented different values of $\varepsilon_{r}^{\prime}$ and $f_{0}$, and considerable alterations in the BW of any of the DRA's were not found. All the DRA's presented return loss lower than $-10 \mathrm{~dB}$, evidencing their potential for technological use, especially for actuation in broadband. In this study, the dielectric constant definition was not considered and the fit of the prototype antenna (DRA) was conducted empirically by S11 parameter. Given this, more investigations on this polymer system acting as DRA, the complete influence of nanoparticles, as well as electrical, dielectric, and magnetic properties are needed.

The biodegradability and the ease of processing stood as great attractive features of the dielectric resonators of this study, mainly when compared to the conventional ceramic resonators, whose preparation, in particular, generally includes calcination, high

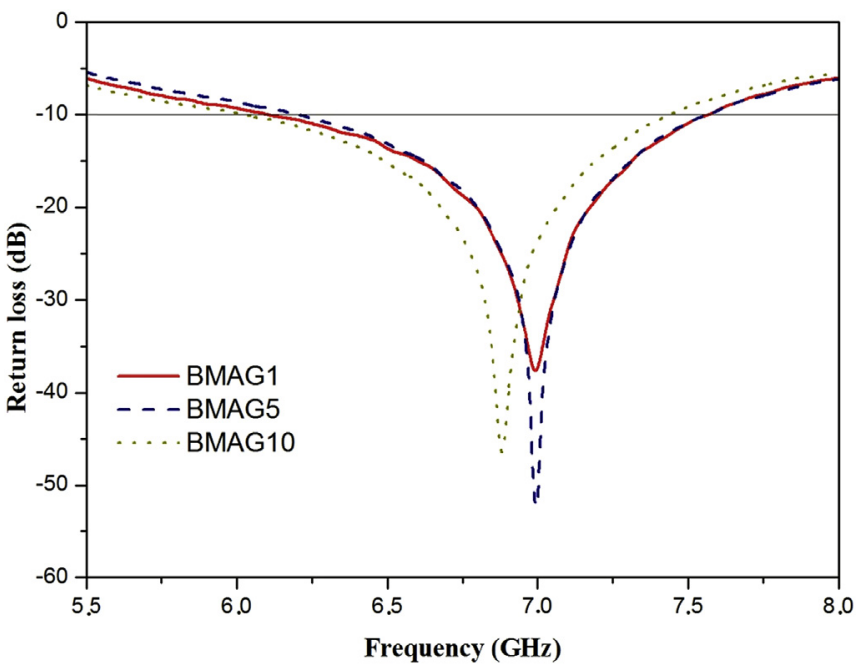

Fig. 12. Experimental results of the nano-biocomposites acting as DRA.

Table 4

- Experimental results for the DRA's.

\begin{tabular}{lllll}
\hline Materials & $\mathrm{RL}(\mathrm{dB})$ & $\varepsilon_{\mathrm{r}}^{\prime}$ & $\mathrm{f}_{\mathrm{o}}(\mathrm{GHz})$ & $\mathrm{BW}(\%)$ \\
\hline BMAG1 & -37.26 & 1.86 & 6.99 & 21.0 \\
BMAG5 & -52.17 & 1.86 & 6.99 & 19.45 \\
BMAG10 & -46.07 & 2.00 & 6.87 & 20.52 \\
\hline
\end{tabular}

RL - Return loss, $\varepsilon_{r}^{\prime}$ - Dielectric permissiveness, $\mathrm{f}_{\mathrm{o}}$ - Resonant frequency, BW Bandwidth (In $-10 \mathrm{~dB})$. energy mechanical milling and thermal treatment which require elevated temperatures, besides considerable resistance to the natural degradation. Considering the characterizations conducted, despite the good results obtained for all the manufactured resonators, BMAG10 presented the best set of properties, especially in relation to the mechanical resistance and dielectric permissiveness.

In a current world scenery in which the call for the sustainable use of the biodiversity and conservation of the environment, the search for alternatives for the petrochemical derivatives, and the dependency on electronic devices is growing, the development of the materials here presented from the raw materials used and with the reunited final properties, represents a relevant contribution which encompasses benefits in the environmental, social, economic, scientific, and technological scopes, with a strong potential for innovation.

\section{References}

[1] C.M. Dües, K.H. Tan, M. Lim, Green as the new Lean: how to use Lean practices as a catalyst to greening your supply chain, J. Clean. Prod. 40 (2013) 93-100 http://dx.doi.org/10.1016/j.jclepro.2011.12.023.

[2] A.L. Borrion, M.C. Mcmanus, G.P. Hammond, Environmental life cycle assessment of lignocellulosic conversion to ethanol: a review, Renew. Sustain. Energy Rev. 16 (7) (2012) 4638-4650, http://dx.doi.org/10.1016 j.rser.2012.04.016.

[3] M.A.E. Mofijur, H.H. Atabani, H.H. Masjuki, M.A. Kalam, B.M. Masum, A study on the effects of promising edible and non-edible biodiesel feedstocks on engine performance and emissions production: a comparative evaluation, Renew. Sustain. Energy Rev. 23 (2013) 391-404, http://dx.doi.org/10.1016/ j.rser.2013.03.009.

[4] S. Raman, A. Mohr, Biofuels and the role of space in sustainable innovation journeys, J. Clean. Prod. 65 (2014) 224-233, http://dx.doi.org/10.1016/ j.jclepro.2013.07.057.

[5] FAO-ONU - Food and Agriculture Organization of the United Nations. Retrieved 21 April 2014, from http://www.fao.org.br.

[6] M.G. Junior, K.M. Novack, V.R. Botaro, T.P. Protásio, A.M. Couto, Caracterização físico-química de fibra e polpas de Bambusa vulgaris Schrad para utilização em compósitos poliméricos, Rev. Latinoam. Metal. Mater. 33 (1) (2013) 33-42.

[7] S. Salma, M. Fayecka, H. Mahbub, Physico-mechanical properties of jute-coir fiber reinforced hybrid polypropylene composites, World Acad. Sci. Eng. Technol. 73 (2013) 1145-1149.

[8] N. Abilash, M. Sivapragash, Environmental benefits of eco-friendly natural fiber reinforced polymeric composite materials, Int. J. Appl. or Innov. Eng. Manag. (IJAIEM) 4847 (2(1)) (2013) 53-59.

[9] G. Rajesh, V.R.P. Atluri, Study on effect of chemical treatments and concentration of jute on tensile properties of long and continuous twisted jute/ polypropylene composite, Adv. Mater. Manuf. Charact. 3 (1) (2013) 395-398, http://dx.doi.org/10.11127/ijammc.2013.02.073.

[10] U.S. Bongarde, V.D. Shinde, Review on natural fiber reinforcement polymer composites, Int. J. Eng. Sci. Innov. Technol. (IJESIT) 3 (2) (2014) 431-436.

[11] B. Steinhoff, S. Wang, I. Alig, Uma análise da degradação do poli(ácido láctico (PLA) induzida pelo processo de transformação, Rev. Plástico Ind. 11 (126) (2009) 78-83

[12] A.L. Silva, L.R.R. Silva, I.A. Camargo, D.L.S. Agostini, D.S. Rosa, D.L.V. Oliveira P.B.A. Fechine, S.E. Mazzetto, Cardanol-based thermoset plastic reinforced by sponge gourd fibers (Luffa cylindrica), Polímeros 26 (1) (2016) 21-29, http:// dx.doi.org/10.1590/0104-1428.2276.

[13] H. Ko, C. Hsi, M. Wang, X. Zhao, Crystallite growth kinetics of $\mathrm{TiO}_{2}$ surface 
modification with $9 \mathrm{~mol} \% \mathrm{ZnO}$ prepared by a coprecipitation process, J. Alloys Compd 588 (2014) 428-439, http://dx doi.org/10.1016/j.jallcom.2013.11.097.

[14] H. Ko, G. Yang, H. Cheng, M. Wang, X. Zhao, Growth and optical properties of cerium dioxide nanocrystallites prepared by coprecipitation routes, Ceram. Int. $40 \quad$ (3) (2014) 4055-4064, http://dx.doi.org/10.1016/ j.ceramint.2013.08.059.

[15] H.M. Rietveld, A profile refinement method for nuclear and magnetics structures, J. Appl. Crystallogr. 2 (2) (1969) 65-71, http://dx.doi.org/10.1107/ S0021889869006558.

[16] X-Pert Highscore Plus, Panalytical B.V. Almelo, Holanda, () 2001 Koninklijke Philips Electronics N.V. All rights reserved.

[17] L. Bleicher, J.M. Sasaki, C.O.P. Santos, Development of a graphical interface for the Rietveld refinement programs DBWS, J. Appl. Crystallogr. 33 (4) (2000) 1189, http://dx.doi.org/10.1107/S0021889800005410.

[18] B.D. Cullity, Elements of X-Ray Diffraction, seco ${ }^{\text {nd }}$ ed., Addison-Wesley 1774, Canada, 1978, pp. 99-102.

[19] P.J. Haines, Principles the Thermal Analysis and Calorimetry, fir ${ }^{\text {st }}$ ed., The Royal Society of Chemistry, Cambridge, 2002.

[20] American Society for Testing and Materials ASTM D3418 Standard Test Method for Transition Temperatures and Enthalpies of Fusion and Crystallization of Polymers by Differential Scanning Calorimetry, 2008 (CD-ROM).

[21] American Society for Testing and Materials ASTM D5026 Standard Test Method for Plastics: Dynamic Mechanical Properties: in Tension, 1995 (CDROM).

[22] American Society for Testing and Materials ASTM D7028 Standard Test Method for Glass Transition Temperature of Polymer Matrix Composites by Dynamic Mechanical Analysis (DMA), 2007 (CD-ROM).

[23] B.W. Hakki, P.D. Coleman, Dielectric resonator method of measuring inductive capacities in the millimeter range, IRE Trans. Microw. Theory Tech. 8 (4) (1960) 402-410, http://dx.doi.org/10.1109/TMTT.1960.1124749.

[24] S.A. Long, M.W. McAllister, L.M. Shen, The resonant cylindrical dielectric cavity antenna, IEEE Trans. Antennas Propag. 31 (3) (1983) 406-412, http:// dx.doi.org/10.1109/TAP.1983.1143080.

[25] A. Petosa, Dielectric Resonator Antenna Handbook, Artech House, Norwood, MA, 2007. ISBN 978-1-59693-206-7.

[26] ICSD - Inorganic Crystal Structure Database, ICSD Collection, File, 1998, pp. 82-449.

[27] C. Pereira, A.M. Pereira, C. Fernandes, M. Rocha, R. Mendes, M.P. FernándezGarcía, A. Guedes, P.B. Tavares, J.M. Grenèche, J.P. Araújo, C. Freire, Superparamagnetic $\mathrm{MFe}_{2} \mathrm{O}_{4}(\mathrm{M}=\mathrm{Fe}, \mathrm{Co}, \mathrm{Mn})$ nanoparticles: tuning the particle size and magnetic properties through a novel one-step coprecipitation route, Chem. Mater. 24 (8) (2012) 1496-1504, http://dx.doi.org/10.1021/ cm300301c.

[28] C.G.S. Souza, Nanopartículas magnéticas multifuncionais: Síntese e propriedades visando aplicação em diagnóstico e terapia em Biomedicina. Dissertação de Mestrado - Instituto de Química de São Carlos, Universidade de São, Paulo, São Paulo, 2011.

[29] S. Laurent, S. Dutz, U.O. Hafeli, M. Mahmoudi, Magnetic fluid hyperthermia: focus on superparamagnetic iron oxide nanoparticles, Adv. Colloid Interface Sci. $166(1-2)$ (2011) 8-23, http://dx.doi.org/10.1016/j.cis.2011.04.003.

[30] M. Arruebo, R. Fernandez-Pacheco, M. Ibarra, J. Santamaria, Magnetic nanoparticles for drug delivery, Nano Today 2 (3) (2007) 22-32, http://dx.doi.org/ 10.1016/S1748-0132(07)70084-1.

[31] M.O. Abdalla, R. Aneja, D. Dean, V. Rangari, A. Russell, J. Jaynes, C. Yates, T. Turner, Synthesis and characterization of noscapine loaded magnetic polymeric nanoparticles, J. Magn. Magn. Mater. 322 (2) (2010) 190-196, http://dx.doi.org/10.1016/j.jmmm.2009.07.086.

[32] T. Sato, T. Iijima, M. Sekin, N. Inagaki, Magnetic properties of ultrafine ferrite particles, J. Magn. Magn. Mater. 65 (2-3) (1987) 252, http://dx.doi.org/ 10.1016/0304-8853(87)90044-8.

[33] V. Pillai, D.O. Shah, Synthesis of high-coercivity cobalt ferrite particles using water-in-oil microemulsions, J. Magn. Magn. Mater. 163 (1-2) (1996) 243-248, http://dx.doi.org/10.1016/S0304-8853(96)00280-6.

[34] P.A. Silva, M.A.M. Jacobi, K.S. Santos, R.V.B. Oliveira, R.S. Mauler, R.V. Barbosa, Efeito do SBS epoxidado como um agente compatibilizante para obtenção de nanocompósitos de SBS/argila cloisite 10A, Polímeros 24 (1) (2014) 129-136, http://dx.doi.org/10.4322/polimeros.2014.061.

[35] P.M. Ajayan, L.S. Schadler, P.V. Braun, Nanocomposite Science and Technology, Wiley-VCH, 2003. ISBN 3527303596.

[36] H.X. Zhao, Robert K.Y. Li, Effect of water absorption on the mechanical and dielectric properties of nano-alumina filled epoxy nanocomposites, Compos. Part A 39 (4) (2008) 602-611, http://dx.doi.org/10.1016/ j.compositesa.2007.07.006.

[37] L. Szczesniak, A. Rachocki, J. Tritt-Goc, Glass transition temperature and thermal decomposition of cellulose powder, Cellulose 15 (3) (2008) 445-4451, http://dx.doi.org/10.1007/s10570-007-9192-2.

[38] E. Corradini, E.M. Teixeira, P.D. Agnelli, J.A. Silva, L.H.C. Mattoso, Thermal stability and degradation kinetic study of white and colored cotton fibers by thermogravimetric analysis, J. Therm. Anal. Calorim. 97 (2) (2009) 415-419, http://dx.doi.org/10.1007/s10973-008-9693-8.

[39] H. Yang, R. Yan, H. Chen, D. Lee, C. Zheng, Characteristic of hemicellulose, cellulose and lignin pyrolysis, Fuel 86 (12-13) (2007) 1781-1788, http:// dx.doi.org/10.1016/j.fuel.2006.12.013.

[40] A.F. Khan, S.R. Ahmad, Chemical Modification and spectroscopic analysis of Jute fibre, Polym. Degrad. Stab. 52 (3) (1996) 335-340, http://dx.doi.org/ 10.1016/0141-3910(95)00240-5.

[41] J.S.V. Canevarolo, Técnicas de Caracterização de Polímeros, Artliber, São Paulo, 2004.

[42] J.P. Pascault, R.J.J. Williams, Glass transition temperature versus conversion relationships for thermosetting polymers, J. Polym. Sci. Part B Polym. Phys. 28 (1) (1990) 85-95, http://dx.doi.org/10.1002/polb.1990.090280107.

[43] J. Zhu, S. Wei, J. Ryu, M. Budhathoki, G. Liang, Z. Guo, In-situ stabilized carbon nanofibers (CNFs) reinforced epoxy nanocomposites, J. Mater. Chem. 20 (23) (2010) 4937-4948, http://dx.doi.org/10.1039/C0JM00063A.

[44] S. Mohanty, S.K. Verma, S.K. Nayak, Dynamic mechanical and thermal properties of MAPE treated jute/HDPE composites, Compos. Sci. Technol. 66 (3-4) (2006) 538-547, http://dx.doi.org/10.1016/j.compscitech.2005.06.014.

[45] S.H. Lim, K.Y. Zeng, C.B. He, Morphology, tensile and fracture characteristics of epoxy-alumina nanocomposites, Mater. Sci. Eng. A 527 (21-22) (2010) 5670-5676, http://dx.doi.org/10.1016/j.msea.2010.05.038.

[46] A.K. Rana, B.C. Mandal, R. Mitra, R. Jacobson, A. Rowell, N. Banerje, Short jute fiber reinforced propylene composites: effect of compatibilizer, J. Appl. Polym. Sci. 69 (2) (1998) 329-338, http://dx.doi.org/10.1002/(SICI)10974628(19980711)69, 2<329::AID-APP14>3.0.CO;2-R.

[47] J.D. Kraus, Antenas, fir ${ }^{\text {st }}$ ed., Editora LTC Livros Técnicos e Científicos, Rio de Janeiro, 1982, p. 553.

[48] C.A. Balanis, Antenna Theory: Analysis and Design, seco ${ }^{\text {nd }}$ ed., John Willey, New York, 1997, p. 941.

[49] S.B. Bibikov, E.I. Kulikovskij, R.S. Sharafiev, A.V. Bychkova, A.A. Ol'khov, Nanocomposites for antenna-feeder systems, antenna theory and techniques (ICATT), in: 2013 IX International Conference on, Odessa, 2013, pp. 500-502, http://dx.doi.org/10.1109/ICATT.2013.6650826.

[50] I.M. Reaney, D. Iddles, Microwave dielectric ceramics for resonators and filters in mobile phone networks, J. Am. Ceram. Soc. 89 (7) (2006) 2063-2072, http://dx.doi.org/10.1111/j.1551-2916.2006.01025.x. 